\title{
Investigation of the structure of gallium oxide glasses by means of positron lifetime measurements
}

\author{
Edmund GOLIS ${ }^{1}$, Jacek FILIPECKI ${ }^{1}$, Manuela REBEN ${ }^{2}$, Jan WASYLAK ${ }^{2}$ \\ ${ }^{1}$ Institute of Physics, Jan Dlugosz University, Al. Armii Krajowej 13/15, 42-200 Czestochowa, Poland \\ ${ }^{2}$ A GH University of Science and Technology, Faculty of Materials Science and Ceramics, \\ Mickiewicz Ave. 30, 30-059 Kraków, Poland \\ * Corresponding author. Tel.: +48-34-3614918; fax: +48-34-366852; e-mail: e.golis@ajd.czest.pl
}

Received June 15, 2010; accepted May 18, 2011; available on-line November 8, 2011

Positron lifetime spectroscopy PALS has been applied to the investigation of the structure of gallium oxide glasses. Three components of the positron lifetime $\tau\left(\tau_{1}\right.$ para- and $\tau_{3}$ ortho-positronium and $\tau_{2}$ average living component) and its intensities $I$ were obtained. The analysis shows that the obtained lifetime components correspond to the occurrence of free volume holes $\left(\tau_{1}\right.$ and $\left.\tau_{3}\right)$ and positron trapping in vacancy-type defects $\left(\tau_{2}\right)$. From the Tao-Eldrup formula we can estimate the size of the free volume. The percentage of intensities of the individual components of the positron lifetime shows that it is strongly dominated by vacancy-type defects.

\section{Gallium oxide glasses / Positron annihilation / Positronium / Structure of glasses}

\section{Introduction}

One of the most active fields in solid state research in recent years is the study of amorphous materials. The aim of this paper is to understand the changes induced by $\mathrm{Pb}$ and $\mathrm{Bi}$ in heavy metal oxide (HMO) glasses, using positron annihilation lifetime spectroscopy (PALS). Positron annihilation is a useful technique to investigate material characteristics. Positrons injected in substances lose their energy through elastic collisions and finally annihilate with electrons through several processes. In the case of non-conductive molecular materials, formation and annihilation of positronium (Ps) take place in addition to the annihilation of the positron. Ps is the bound state of the positron and electron having an atomic radius comparable to that of the hydrogen atom. It exists in two spin states. One is called para-positronium ( $\mathrm{p}-\mathrm{Ps}$ ), in which the positron and electron spins are antiparallel. The other state, ortho-positronium (o-Ps), corresponds to parallel particle spins. The process, called pick-off annihilation, reduces the o-Ps lifetime in polymers to a few nanoseconds. Ps cannot form in materials with high electron densities. The positronium formation probability and lifetime are extremely sensitive to the electron density surrounding Ps. The o-Ps localises in the space between and along polymer chains and at chain ends (free volume holes), and the lifetime gives an indication on the mean radii of these holes [1-4]. The original free volume theory for the positron annihilation in molecular substances was proposed by Brandt, Berko and Walker [5]. Thus the o-Ps has a slower annihilation rate and longer lifetime. Tao and Eldrup et al. [6,7] derived an equation to correlate experimentally observed o-Ps lifetimes and the dimensions of free volume holes, mainly in polymers.

Glasses based on oxides of germanium, gallium, tellurium and antimony are often referred to as heavy metal oxide (HMO) glasses. They are promising materials for photonics and optoelectronics, as passive and optical fibres, and for optical switching, due to their smaller phonon energy and larger refraction indices than silicate glasses [8,9]. Gallium bismuthate glasses appear to be promising host materials for waveguide devices in microwaves telecommunication windows, broad band amplifier and high power laser applications [2]. They offer better chemical stability than fluoride glasses. Glasses including gallium systems are characterized by high optical nonlinearity, high magneto-optic effect and extended IR transparency. $\mathrm{Ga}_{2} \mathrm{O}_{3}$ is a heavy metal oxide, and when it is introduced in the glass matrix, it may influence the physical properties. Many recent investigations on the role of $\mathrm{Ga}_{2} \mathrm{O}_{3}$ in various glass matrixes are available in the literature [8-11]. Lead and bismuth cations have the greatest mass and the smallest field strength among the non-radioactive cations, but their oxides themselves do not form glasses under normal cooling conditions. It is necessary to add a stabilizer, whose role in the investigated glasses meet gallium oxide [12]. The structure of heavy metal oxide glasses 
is interesting because such information helps better understanding glass processing [8].

\section{Experimental}

Two $\mathrm{PbO}-\mathrm{Bi}_{2} \mathrm{O}_{3}-\mathrm{Ga}_{2} \mathrm{O}_{3}$ glass systems were prepared by using reagent grade chemicals $\mathrm{Bi}_{2} \mathrm{O}_{3}, \mathrm{Ga}_{2} \mathrm{O}_{3}$ and $\mathrm{PbO}$ as starting materials (Table 1 ). The homogenised mixtures were melted at $1100^{\circ} \mathrm{C}$ in covered platinum crucibles in an electric furnace and then the melts were quickly undercooled at room temperature by pouring onto stainless-steel plates. The melting time was $30 \mathrm{~min}$. The glass transition temperatures $\left(T_{\mathrm{g}}\right)$ and crystallization temperatures $\left(T_{\mathrm{cr}}\right)$ of the samples were determined in the temperature range $20-1000^{\circ} \mathrm{C}$ using a Perkin Elmer DTA 7 device. Differential thermal analysis (DTA) traces were recorded at the heating rate $10^{\circ} \mathrm{C} / \mathrm{min}$ (Fig. 1). The amorphous state was confirmed by X-ray diffraction using a DRON-1.5 diffractometer (Fig. 2).

The PALS measurements were performed at room temperature using a conventional fast-fast coincidence system with an ORTEC spectrometer. The time resolution of the system was $0.270 \mathrm{ps}$ (full width at half maximum). Each specimen consisted of a system of circular layers, of total size $10 \mathrm{~mm}$ diameter and $1.2 \mathrm{~mm}$ thickness. A ${ }^{22} \mathrm{Na}$ isotope positron source of $7.4 \times 10^{5} \mathrm{~Bq}$ activity was situated between two samples, forming a "sandwich" system. In general, each PALS spectrum, recorded with a total number of

Table 1 Chemical composition of the investigated $\mathrm{PbO}-\mathrm{Bi}_{2} \mathrm{O}_{3}-\mathrm{Ga}_{2} \mathrm{O}_{3}$ glasses.

\begin{tabular}{c|c|c|c}
\hline \multirow{2}{*}{ Glass No. } & \multicolumn{3}{|c}{ Glass composition [mol.\%] } \\
\cline { 2 - 4 } & $\mathrm{PbO}$ & $\mathrm{Bi}_{2} \mathrm{O}_{3}$ & $\mathrm{Ga}_{2} \mathrm{O}_{3}$ \\
\hline 1 & 60 & 10 & 30 \\
2 & 20 & 50 & 30 \\
\cline { 2 - 4 }
\end{tabular}

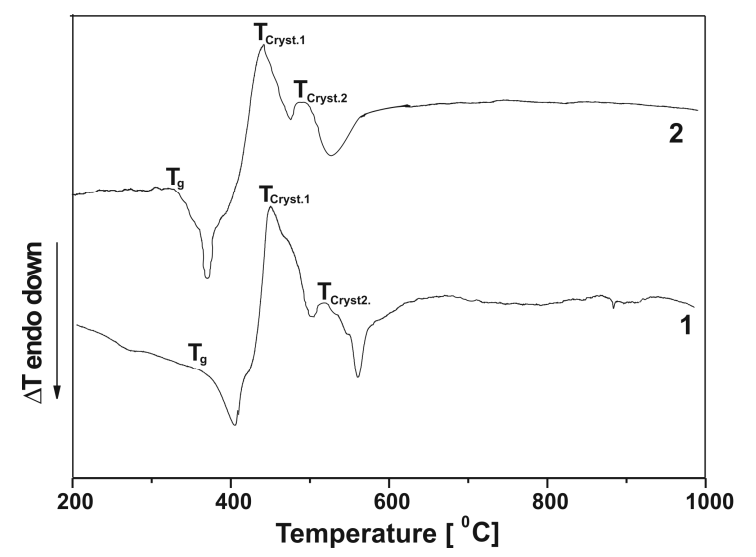

Fig. 1 DTA curves of $\mathrm{PbO}-\mathrm{Bi}_{2} \mathrm{O}_{3}-\mathrm{Ga}_{2} \mathrm{O}_{3}$ glasses.

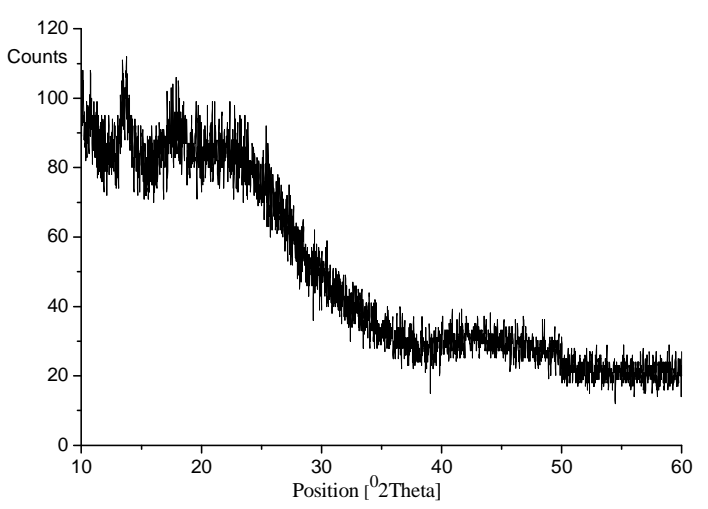

Fig. 2 XRD pattern of the green glass 1.

$2 \times 10^{6}$ counts, which is high enough to obtain a good analysis, was measured five times to check its reproducibility. The lifetime spectra were analysed by the common "Microcomputer program LT" designed by Kansy [13].

\section{Results and discussion}

Analysis of the DTA curves of glasses 1 and 2 indicates, besides the thermal effects characteristic (Table 2) of phase transitions occurring in glassy materials, very strong exothermic peaks near 468 and $509^{\circ} \mathrm{C}$ (Fig. 1). The thermal stability parameter $\Delta T$ was calculated for both glasses. The value of $\Delta T$ is higher for glass 2, which indicates that glass 2 is characterized by higher thermal stability.

The positron lifetime spectra were analyzed using the LT computing program with a three-component model (Fig. 3 shows a typical lifetime spectrum). Therefore, only three-component results are presented here. In glass materials, the short-lived component is usually attributed to p-Ps annihilation. Therefore, the shortest lifetime $\tau_{1}$ was fixed at $125 \mathrm{ps}$ (the p-Ps lifetime) during the fitting. The intermediate lifetime $\left(\tau_{2} \sim 0.3 \mathrm{~ns}\right)$ is due to the annihilation of free positrons with electrons in the bulk material and positron trapping modes [4,14-16]. The results of the calculation of the mean values of the positron lifetimes for the investigated samples showed the existence of a long-lived component in the positron annihilation lifetime spectra.

According to the common interpretation we attribute the longest component $\tau_{3}$ to the pick-off annihilation of o-Ps trapped by free volumes. In any given sample, all the free volume holes are not of the same size. The LT results are the averaged values, but the real long-lived annihilation events have some time-distribution around the averaged value. So, the concept of the average free volume size is used in practice. The variations of the intermediate lifetime $\tau_{2}$ 
Table 2 Thermal characteristics of $\mathrm{PbO}-\mathrm{Bi}_{2} \mathrm{O}_{3}-\mathrm{Ga}_{2} \mathrm{O}_{3}$ glasses.

\begin{tabular}{c|c|c|c|c|c}
\hline Glass No. & $\begin{array}{c}T_{\mathrm{g}} \\
{\left[{ }^{\circ} \mathrm{C}\right]}\end{array}$ & $\begin{array}{c}T_{\max \mathrm{cr} 1} \\
{\left[{ }^{\circ} \mathrm{C}\right]}\end{array}$ & $\begin{array}{c}T_{\max \mathrm{cr} 2} \\
{\left[{ }^{\circ} \mathrm{C}\right]}\end{array}$ & $\begin{array}{c}\Delta T_{1}=T_{\max \mathrm{cr}}-T_{\mathrm{g}} \\
{\left[{ }^{\circ} \mathrm{C}\right]}\end{array}$ & $\begin{array}{c}\Delta T_{1}=T_{\max \mathrm{cr}}-T_{\mathrm{g}} \\
{\left[{ }^{\circ} \mathrm{C}\right]}\end{array}$ \\
\hline 1 & 390 & 468 & 509 & 78 & 119 \\
2 & 345 & 467 & 490 & 122 & 145 \\
\hline
\end{tabular}

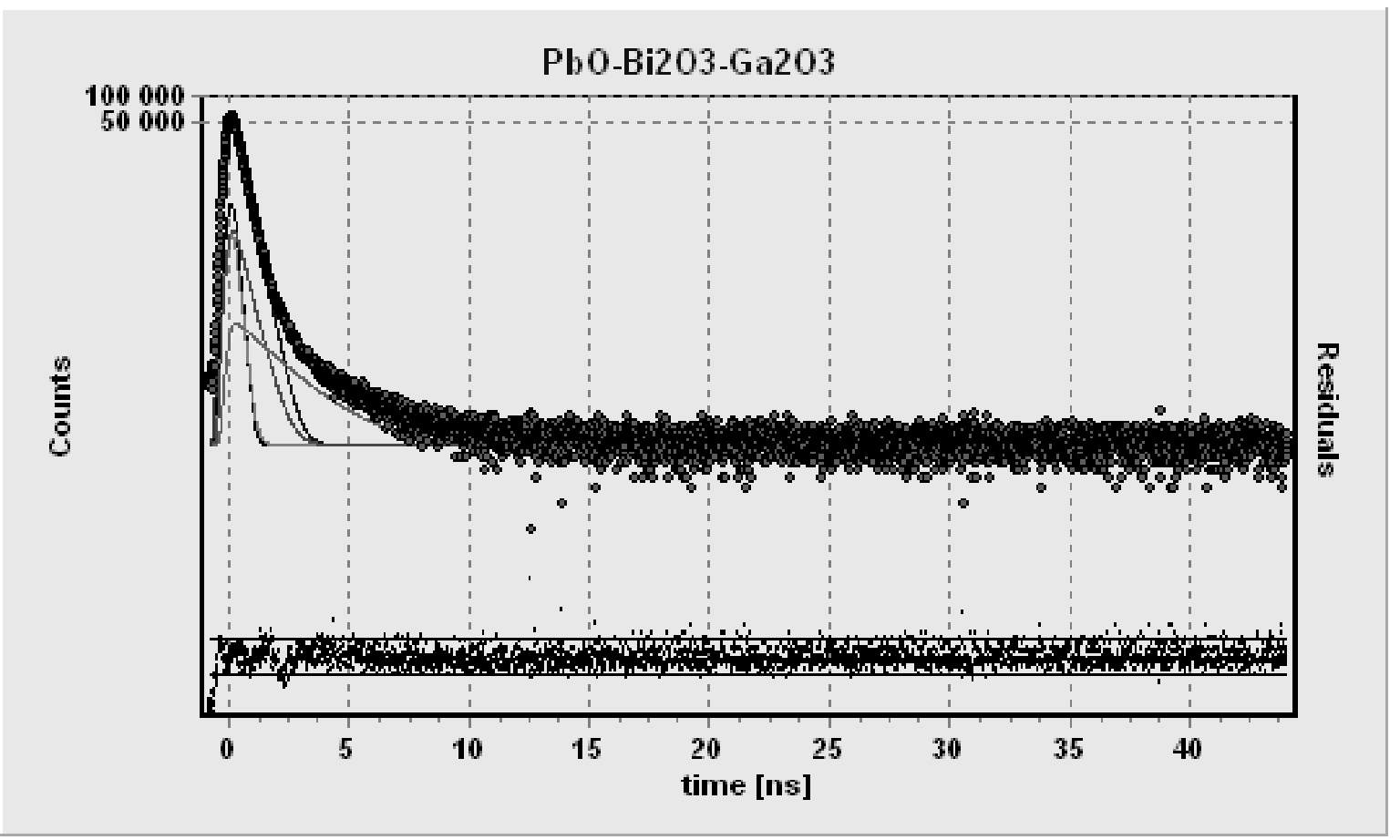

Fig. 3 Typical lifetime spectrum for the investigated $\mathrm{PbO}-\mathrm{Bi}_{2} \mathrm{O}_{3}-\mathrm{Ga}_{2} \mathrm{O}_{3}$ samples.

Table 3 Mean values of the lifetimes $\tau_{2}, \tau_{3}$ and relative intensities $I_{2}, I_{3}$ for $\mathrm{PbO}-\mathrm{Bi}_{2} \mathrm{O}_{3}-\mathrm{Ga}_{2} \mathrm{O}_{3}$ glasses.

\begin{tabular}{c|c|c|c|c}
\hline Glass No. & $\tau_{2}[\mathrm{~ns}]$ & $I_{2}[\%]$ & $\tau_{3}[\mathrm{~ns}]$ & $I_{3}[\%]$ \\
\hline $\mathbf{1}$ & $0.324 \pm 0.0064$ & $92.180 \pm 0.042$ & $2.321 \pm 0.014$ & $2.216 \pm 0.019$ \\
$\mathbf{2}$ & $0.318 \pm 0.0065$ & $93.789 \pm 0.044$ & $2.003 \pm 0.012$ & $1.307 \pm 0.018$ \\
\hline
\end{tabular}

and o-Ps pick-off lifetime $\tau_{3}$ and theirs intensities for the investigated samples are presented in Table 3.

The studies show that in samples 1 and 2 the component $\tau_{2}$ does not change beyond the limits of the experimental errors. The value of the longest component $\tau_{3}$ and its intensity $I_{3}$ are much higher in the case of glass 1. This can be explained by the arrangement of $\mathrm{PbO}$ in the glass structure. $\mathrm{PbO}$ plays the role of glass former and makes the structure looser. In the case of glass $2 \mathrm{PbO}$ acts as a glass former and modifier that thickens the structure. Further investigations of gallium oxide glasses using PALS techniques will include glasses with other percentages of $\mathrm{PbO}$ and $\mathrm{Bi}_{2} \mathrm{O}_{3}$. Structure investigations will allow improving the production of glasses for technological applications including gallium systems characterized by high optical nonlinearity and high magneto-optic effect.

\section{References}

[1] Y.C. Jean, NATO Advanced Research Workshop, Advances with Positron Spectroscopy of Solids and Surfaces, Varenna, Italy, July 16-17, 1993.

[2] R.A. Pethrick, Prog. Polym. Sci. 22 (1997) 1.

[3] M. Hyla, J. Filipecki, Z. Mandecki, R.I. Mervinskii, J. Non-Cryst. Solids 232-234 (1998) 446-449.

[4] M. Hyla, J. Filipecki, J. Swiatek, J. Non-Cryst. Solids 352 (2006) 2726-2230.

[5] W. Brandt, S. Berko, W.W. Walker, Phys. Rev. 120 (1960) 1289-1299.

[6] S.J. Tao. J. Chem. Phys. 6 (1972) 5499-5506.

[7] M. Eldrup, D. Lightbody, J.N. Sherwood, Chem. Phys. 63 (1981) 51-58.

[8] D. Dorosz, Mol. Quant. Acoust. 25 (2004) 79-87. 
E. Golis et al., Investigation of the structure of gallium oxide glasses ...

[9] D. Lezal, J. Pedlikova, P. Kostka, J. Bladuska, M. Poulain, J. Zavadil, J. Non-Cryst. Solids 284 (2001) 288-295.

[10] C.T. Tan, T.N. Ooi, S.K. Lahiri, J. Mater. Sci. Lett. 14 (1995) 405-407.

[11] M. Janewicz, K. Kopczyński, Z. Mierczyk, Proc. SPIE 1793 (1992) 158.

[12] S. Simon, V. Simon, Mater. Lett. 58 (2004) 3778-3781.
[13] J. Kansy, Nucl. Instr. Meth. Phys. Res. A 374 (1996) 235-244.

[14] R. Krause-Rehberg, H.S. Leipner, Positron Annihilation in Semiconductors, Springer, Berlin, 1999.

[15] B. Bergersen, M.J. Stott, Solid State Commun. 7, (1969) 1203-1208.

[16] R. Krause-Rehberg, H.S. Leipner, Appl. Phys. A 64 (1997) 457-462.

Proceeding of the XVI International Seminar on Physics and Chemistry of Solids, Lviv, June 6-9, 2010. 